\title{
The Vietnamese Version of the Nursing Critical Thinking in Clinical Practice Questionnaire: Translation and Psychometric Evaluation
}

\author{
Tuan Van Nguyen ( $\nabla$ nguyentuan.ctump@gmail.com ) \\ Trường Đại học Y Dược Cần Thơ https://orcid.org/0000-0001-7597-1141 \\ Hsueh-Erh Liu \\ Chang Gung University
}

\section{Research article}

Keywords: The Vietnamese Version of the Nursing Critical Thinking in Clinical Practice Questionnaire, Translation and Psychometric Evaluation

Posted Date: April 8th, 2020

DOl: https://doi.org/10.21203/rs.3.rs-19956/v1

License: (c) (1) This work is licensed under a Creative Commons Attribution 4.0 International License. Read Full License

Version of Record: A version of this preprint was published on March 11th, 2021. See the published version at https://doi.org/10.1002/nop2.834. 


\section{Abstract}

Background: Many instruments measure critical thinking ability in nursing education. The Nursing Critical Thinking in Clinical Practice Questionnaire (N-CT-4 Practice) is a new tool to measure the level of critical thinking ability of nurses in a clinical setting. However, no study has evaluated the psychometric properties of the N-CT-4 Practice in Vietnam. Therefore, this study translated and evaluated the validity and reliability of the Vietnamese version of the Nursing Critical Thinking in Clinical Practice Questionnaire (V-N-CT-4 Practice).

Results: The V-N-CT-4 Practice questionnaire retained the meaning of the original English version and was clear, explicit and easy for nurses to understand. The item content validity index of the V-N-CT-4 Practice was 1.0. The Cronbach's alpha for the overall scales was .98. The intraclass correlation coefficient was .81. Confirmatory factor analysis indicated that this Vietnamese version fit the proposed model.

Conclusions: The findings suggested that the V-N-CT-4 Practice has acceptable reliability and validity for Vietnamese nurses in a clinical setting. Nurse managers and educators can use the V-N-CT-4 Practice to measure the level of critical thinking ability of Vietnamese clinical nurses and make international comparisons possible.

\section{Background}

Critical thinking has been described from multidisciplinary perspectives, with disparate definitions related to the concepts of cognition, attitude, process, and skills. Many nursing scholars agree that critical thinking is necessary and valuable in nursing education and practice, even though there is no clear consensus on a definition [1-4]. In nursing practice, critical thinking is a cognitive process that represents the competence to apply reasoning with the desire to decrease errors in decision-making [5-7]. Nurses apply critical thinking skills daily to assess, plan and provide quality patient care [8]. In addition, critical thinking ability has been associated with clinical decision-making [9-13], nursing competence [14], nursing processes [15-17], nurse workplace production and problem-solving ability [18], and research utilization [19].

The measurement of the level of critical thinking ability has been a concern of numerous studies in the last several decades [20]. Based on a review of 34 studies, sixteen different tools were identified for measuring the concept of critical thinking. The most commonly used instruments are standardized, such as the California Critical Thinking Disposition Inventory (CCTDI), California Critical Thinking Skills Test (CCTST) [21], Health Sciences Reasoning Test (HSRT) [22], and Watson-Glaser Critical Thinking Appraisal (WGCTA) [23]. However, the review also found that most of the instruments were used in nursing education but not in nursing clinical practice [24].

The Nursing Critical Thinking in Clinical Practice (N-CT-4 practice) questionnaire is a relatively newly developed self-administered questionnaire that was designed to measure the critical thinking ability of nurses who work in clinical areas. The psychometric testing of the original N-CT-4 Practice questionnaire 
showed good validity and reliability [20]. However, this questionnaire was not available in Vietnam, which has extensive nursing work in the clinical area. Therefore, this study aimed to translate the English N-CT-4 Practice Questionnaire into Vietnamese (V-N-CT-4 Practice) and to examine its validity and reliability with a sample of Vietnamese clinical nurses.

\section{Methods}

\subsection{Translation process}

The forward- and back-translation process was adopted from principles established in previously published guidelines [25]. The process included 5 steps: (1) the survey was forward-translated into Vietnamese by two independent bilingual translators; (2) a committee approach among the two translators and the bilingual researcher was used to obtain consensus on the final Vietnamese version; (3) the Vietnamese version was blindly back-translated into English by two different independent bilingual translators, and again, the committee approach and consensus were reached on the English back-translation version; (4) the English back-translation version was compared with the original English version by two independent native English-speaking experts. These experts evaluated whether the meaning of these two versions was similar using a five-point Likert scale ( $1=$ strongly disagree, $2=$ disagree, $3=$ neutral, $4=$ agree, and $5=$ strongly agree). If uncertainties and differences could not be resolved, steps 1 through 4 were repeated. (5) The Vietnamese version was sent to three experts who were familiar with the clinical nursing setting. They were asked to judge each item of the instrument for translation and content equivalence using a 4-point Likert scale $(1=$ not relevant, $2=$ unable to assess relevance; 3 = relevant but needs minor alteration; and 4 = very relevant and succinct). The proportion of the experts' agreement was used for equivalent assessment of the translated instrument.

\subsection{Psychometric evaluation}

The validity of the V-N-CT-4 Practice was assessed with both content and construct validity. The method suggested by Lynn (1986) and Polit, Beck and Owen (2007) was used to identify the content validity on the item level content validity index (I-CVI) $[26,27]$. Three experts assessed the relevance of each item on a 4-point Likert scale, from (1) not relevant to (4) very relevant. Lynn (1986) stated that the I-CVI must be 1.0 when there were five or fewer experts. The construct validity was evaluated by confirmatory factor analysis (CFA). Model fit was explored with several procedures because different authors have recommended using a number of indicators to identify the fit of models $[28,29]$.

The reliability of V-N-CT-4 Practice was evaluated by both internal consistency and test-retest reliability. The former was assessed with the Cronbach's alpha coefficient. The scale was considered to display acceptable, good, or excellent internal consistency when this index was more than $.7, .8$ or .9, respectively. The latter was evaluated by the intraclass correlation coefficient (ICC), and a minimum value of .7 was considered satisfactory [30].

\subsection{Participants}


The participants were clinical nurses recruited based on convenience from the internal medicine, surgery, intensive care unit (ICU), emergency department (ED), and anesthesiology and recovery departments of three general hospitals located in Can Tho City, southwestern part of Vietnam. The required sample size was 545, with 5 participants per variable [31], which was treated as one item in the V-N-CT-4 Practice questionnaire. The eligibility criteria for nurses included (1) work as a clinical nurse; (2) 20 years old and above; and (3) full-time employment. All working nurses in these departments were invited to participate in this study. Nurses absent during data collection were excluded.

\subsection{Ethical considerations and study procedure}

This study adhered to the ethical principles in congruence with the Declaration of Helsinki adhered [32] and was permitted ethical approval by the ethical review board of the first author's institution.

Once approved, the researcher contacted three hospitals and obtained a name list of nurses from each hospital. The research group contacted and invited these nurses to participate in this study. The research participants were provided both verbal and written information relating to the purpose, benefits and risks of research as well as procedures to assure anonymity, confidentiality, and voluntary participation to potential subjects. Once they agreed, the consent form was signed, and a questionnaire was sent to them directly. It took approximately 20 minutes for participants to complete the V-N-CT-4 Practice questionnaire and provide demographic characteristics.

\subsection{Instruments}

The N-CT-4 Practice questionnaire was developed by Zuriguel-Pérez (2017) and based on the theoretical model of Alfaro-LeFevre (2016). It was a specific tool developed to measure the level of critical thinking ability of nurses in clinical practice environments. This scale has 109 items with a 4-point Likert response format ( 1 = never or almost never, 2 = occasionally, 3 = often and $4=$ always or almost always). There are four dimensions: personal characteristics (Prs, 39 items); intellectual and cognitive abilities (Int, 44 items); interpersonal abilities and self-management (Atg, 20 items); and technical abilities (Tcn, 6 items). The total score ranges between 109 and 436, and the levels of critical thinking are categorized as low level (score < 329), moderate level (score between 329 and 395), and high level (score > 395). By expert evaluation, the original results from 399 clinical nurses had an I-CVI of .85, a total Cronbach's alpha coefficient of .96, and an ICC of .77. The goodness-of-fit indices in CFA were $\chi 2 / \mathrm{df}=1.95$, RMSEA $=.055$, SRMR $=.65, \mathrm{CFI}=.629$, and TLI $=.621$, indicating that the N-CT-4 Practice was in keeping with the fourdimensional model proposed by Alfaro-Levre [20].

\subsection{Statistical analysis}

SPSS for Window version 22.0 (IBM Corp., Armonk, NY, USA) was used to analyze the data. Descriptive statistics were used to summarize the characteristics of the participants. The I-CVI was calculated to assess the content validity of the V-N-CT-4 Practice using Microsoft Excel. CFA was conducted using AMOS version 22.0 to evaluate construct validity. The goodness-of-fit of the model was assessed by 
using the indices and criteria: chi-square test ( $\chi 2$; nonsignificant). Because chi-square is sensitive to sample size, we evaluated the goodness-of-fit index based on the ratio between chi-square and the degrees of freedom $(\chi 2 / d f ;<3)$, the root mean square error of approximation (RMSEA; <.06), the standardized root mean square residual (SRMR; <.08), the comparative fit index (CFI >.95 is a good fit), and the Tucker-Lewis index (TLI $>.95$ is a good fit; $0<T L I<1$ can be acceptance) $[28,29]$. The Cronbach's alpha coefficient was used to evaluate the internal consistency, and a value of $a \geq .7$ was acceptable. The ICC was used to assess the test-retest reliability for a 2-week period, and the value of ICC $\geq .7$ was satisfactory [30].

\section{Results}

\subsection{Characteristics of participants}

The questionnaire was completed by 545 clinical nurses. Overall, the majority were female $(71.4 \%)$, and half of nurses were married (50.5\%). The age and years of work experience ranged from 21-60 years (median $=29$ ) and 1-41 years (median = 5), respectively. Most of the nurses had diplomas and associate degrees (73.9\%), followed by bachelor's and graduate degrees $(26.1 \%)$. The present working areas of the samples were internal medicine (38.5\%), surgery (33.4\%), and critical care units $(28.1 \%)$.

\subsection{Translation equivalence}

All three bilingual experts conducted rating independently, and the results showed that the V-N-CT-4 Practice questionnaire retained the meaning of the original English version and that the language used in the Vietnamese version was clear, explicit, and easy for nurses to understand. The original English version and the back-translated English version were compared by two native English speakers. They strongly agreed and agreed that the back-translated version preserved the equivalent meaning of the original English version for all items $(\mathrm{I}-\mathrm{CVI}=1.0)$. Only one item of the back-translated English version needed to be modified. Specifically, the English version was "I recognize my own emotions", and the backtranslation was "I recognize my emotion". Emotions are plural, meaning more than one emotion. These experts suggested modifying it. However, nouns in Vietnamese do not distinguish singular or plural, so the two sentences mentioned above have the same meaning in Vietnamese language.

\subsection{Reliability}

The overall Cronbach's alpha coefficient of the V-N-CT-4 Practice was .98, showing excellent internal consistency [30,33]. The Cronbach's alpha for the four subscales ranged from .86 to .97 , indicating the good reliability of each subscale. The ICC for the V-N-CT-4 Practice was .81, and the ICC for the four subscales ranged from .76 to $.86(p<.001)$, indicating good stability for the 2-week period (table 1$)$. 
Table 1. Reliability and construct validity of the Vietnamese and original English versions

\begin{tabular}{|c|c|c|c|c|c|c|c|c|}
\hline \multirow[b]{2}{*}{ Value } & \multicolumn{4}{|c|}{ V-N-CT-4 Practice } & \multicolumn{4}{|c|}{ N-CT-4 Practice } \\
\hline & Cronbach's a & ICC & CFA & & Cronbach's a & ICC & CFA & \\
\hline Total score & .98 & .81 & $\chi 2 / d f$ & 2.87 & .96 & .77 & $\chi 2 / d f$ & 1.95 \\
\hline Subscale: Prs & .95 & .86 & RMSEA & .059 & .89 & .70 & RMSEA & .055 \\
\hline Int & .97 & .76 & SRMR & .063 & .94 & .77 & SRMR & .65 \\
\hline Atg & .95 & .80 & $\mathrm{CFI}$ & .73 & .86 & .84 & $\mathrm{CFI}$ & .629 \\
\hline Tcn & .86 & .84 & TLI & .72 & .78 & .76 & TLI & .621 \\
\hline
\end{tabular}

Note: Prs: Personal dimension; Int: Intellectual and cognitive dimension; Atg: Interpersonal and selfmanagement dimension; Tcn: Technical dimension; RMSEA: Root mean square error of approximation; SRMR: Standardized root mean square residual; CFI: Comparative fit index; TLI: Tucker Lewis index

\subsection{Content validity}

The V-N-CT-4 Practice questionnaire had an excellent item level content validity index $(\mathrm{I}-\mathrm{CVI}=1.0)$, indicating that all items were scored as acceptable. However, the three experts suggested that the V-N-CT4 Practice should be shorter to help nurses focus their attention and maintain concentration while answering the 109 items.

\subsection{Construct validity}

All the values for estimated parameters for the model were statistically significant in all cases $(p<.001)$, consistent with what was expected. None of the variances or correlations revealed values considered to be unsuitable to the extent that the proposal would be invalidated. However, the modification indices recommended that the fit would be better when the residuals between items 7 and 8, 16 and 17, 20 and 21, 38 and 39, 40 and 41, 47 and 48, 49 and 50, 78 and 79, 94 and 95, and 108 and 109 were correlated. The graphic representation (path diagram) of the model is shown in Figure 1. Convention dictates that squares declare measured variables (e.g., i1 is item 1 in the V-N-CT-4 Practice questionnaire) and that circles indicate latent variables (e.g., personal dimension, intellectual dimension). The value that is revealed with the single-headed arrows between the circles and the squares shows the factor loading; the double-headed arrows show the correlations between pairs of variables. CFA reported that the correlation between the pairs of variables in the model-personal and intellectual, personal and interpersonal, personal and technical, intellectual and interpersonal, intellectual and technical, and interpersonal and technical-was $.76, .68, .59, .87, .80, .86$, respectively $(p<.001)$, indicating that four dimensions of the model are adequate. 
The results of the chi-square test showed that the assumption of a perfect model needed to be rejected $\left(\chi^{2}=16569.06 ; p<.0001\right)$, indicating that the fit of the data to the hypothesis of a perfect model was not entirely satisfied. The adjusted indices based on covariance showed optimal values: $\chi 2 / d f=2.87, \mathrm{RMSEA}$ $=.059, \mathrm{SRMR}=.063$, although the incremental measurement indices produced values below the level of good model fit: $\mathrm{CFI}=.73$, and TLI $=.72$ (table 1 ). Overall, the findings of the goodness-of-fit indices indicated that the structure of the proposed questionnaire is acceptable.

\section{Discussion}

The N-CT-4 Practice questionnaire is a new scale used to measure the level of critical thinking ability of nurses in their daily practice, and both the Spanish and English versions show good psychometric properties [20]. This is the first translation to obtain the Vietnamese version of the N-CT-4 Practice and verify its psychometric properties. The results showed that the V-N-CT-4 Practice questionnaire has satisfactory psychometric properties. Overall, the V-N-CT-4 Practice had good translation equivalence, good and excellent internal consistency, and excellent I-CVI. It has similar goodness-of-fit indices in CFA values to the original English version.

The process of forward- and back-translation was performed fluently in this study, and we only slightly modified the content of some items (items 15, 31, 81, and 83). Particularly, item 15 changed the phrases of "khó khăn để vượt qua" to "thách thức để vượt qua"; item 31 changed the words "càng lớn" to "càng nhiều"; item 81 changed the phrases "làm thế nào để tôi trau dồi nó" to "cách thức tôi đã tìm hiểu"; and item 83 changed the words "cơ quan" to "tổ chức". The findings of the I-CVI suggested that all items were scored as satisfactory.

Regarding the reliability of the questionnaire, the total Cronbach's alpha coefficient had excellent qualifies $(a=.98)$, which was similar to the values in the original English version $(a=.96)$. All four subscales also had good and excellent internal consistency (ranging from .86 to .97), which was consistent with the original English version (ranging from .78 to .94). Moreover, the findings of test-retest reliability for the overall scale $(I C C=.81)$ and the four subscales (ranging between .76 and .86$)$ indicated that the V-N-CT-4 Practice possesses good stability over time, which was consistent with the original English version [20, 34].

In this study, the results from a CFA on data from 545 clinical nurses indicated that the psychometric properties of the V-N-CT-4 Practice questionnaire are satisfactory. Specifically, most of the values used to evaluate the goodness-of-fit are satisfactory $(\chi 2 / d f=2.87, \mathrm{RMSEA}=.059, \mathrm{SRMR}=.063$, and TLI $=.72)$. However, the value of CFI was only close to the appropriate level [29]. These findings are similar and somewhat better than those for the original English version, which reported a very high SRMR value $($ SRMR $=.65>08)$ (table 1). These findings also confirmed that the V-N-CT-4 Practice questionnaire is consistent with the 4-Circle Critical Thinking Model of Alrafo-LeFevre (2016), which was the theoretical basis of the N-CT-4 Practice questionnaire. Therefore, the psychometric properties of the V-N-CT-4 Practice 
questionnaire are satisfactory and can be applied to examine the level of critical thinking ability in Vietnamese clinical nurses.

A limitation of this study was that the samples were recruited from three public hospitals in the southwestern part of Vietnam and may not fully represent all nurses in Vietnam. However, the large sample size did represent the availability of this tool in Vietnam in general.

\section{Conclusions}

In summary, the current study provides evidence that the V-N-CT-4 Practice questionnaire has acceptable reliability and validity and can be used to assess the level of critical thinking ability in Vietnamese clinical nurses. Therefore, nurse managers and educators can apply this scale to assess the level of critical thinking ability of clinical nurses in the future.

The use of the V-N-CT-4 Practice questionnaire supplies a valuable opportunity to evaluate critical thinking ability in nursing practice and produce additional opportunities for cross-cultural comparison studies between Vietnamese and other countries. Thus, further exploration and training associated with critical thinking can be achieved by using this valid instrument.

\section{Abbreviations}

CFA: Confirmatory Factor Analysis; CFI: Comparative Fit Index; ICC: Intraclass correlation coefficient; I-CVI: the Item Content Validity Index; N-CT-4 Practice: Nursing Critical Thinking in Clinical Practice Questionnaire; RMSEA: Root Mean Square Error of Approximation; SRMR: Root Mean Square Residual; TLI: Tucker-Lewis Index; V-N-CT-4 Practice: The Vietnamese version of the Nursing Critical Thinking in Clinical Practice Questionnaire.

\section{Declarations}

\section{Ethics approval and consent to participate}

This study granted ethical approval from the ethics review board of Can Tho Univerisity of Medicine and Pharmacy, Can Tho City, Vietnam (No: 1658/QĐ-ĐHYDCT). The informed consent obtained from study participants was written prior to data collection.

Consent for publication: Not applicable

\section{Availability of data and materials}

Data of this study is available from the first author on appropriate request.

\section{Competing interests}


Authors have no competing interests.

\section{Funding}

This research did not receive any specific grant from funding agencies in the public, commercial, or notfor-profit sectors.

\section{Authors' contributions}

Study design: VTN, HEL; Data collection: VTN; Data analysis: VTN; Manuscript writing: VTN, HEL. All authors read and approved the manuscript.

\section{Acknowledgments}

The authors would like to thank the expert panel and translators, research assistants, hospitals, and all clinical nurses participating in this study. We are indebted to the study participants and would like to dedicate the research findings to measuring and improving critical thinking ability for Vietnamese clinical nurses.

\section{References}

1. Zuriguel-Pérez E, Lluch Canut MT, Falcó Pegueroles A, Puig Llobet M, Moreno Arroyo C, Roldán Merino J: Critical thinking in nursing: Scoping review of the literature. International journal of nursing practice 2015, 21(6):820-830.

2. Shoulders $B$, Follett $C$, Eason J: Enhancing critical thinking in clinical practice: implications for critical and acute care nurses. Dimens Crit Care Nurs 2014, 33(4):207-214.

3. Chan ZC: A systematic review of critical thinking in nursing education. Nurse Educ Today 2013, 33(3):236-240.

4. Mundy K, Denham SA: Nurse educators-still challenged by critical thinking. Teaching and Learning in Nursing 2008, 3(3):94-99.

5. Chao S-Y, Liu H-Y, Wu M-C, Clark MJ, Tan J-Y: Identifying critical thinking indicators and critical thinker attributes in nursing practice. Journal of Nursing Research 2013, 21(3):204-210.

6. Shinnick MA, Woo MA: The effect of human patient simulation on critical thinking and its predictors in prelicensure nursing students. Nurse Education Today 2013, 33(9):1062-1067.

7. Alfaro-Lefevre R: Critical Thinking, Clinical Reasoning and Clinical Judgment: A Practical Approach, Pageburst E-book on Kno: Elsevier Health Sciences; 2016.

8. Bambini D, Washburn J, Perkins R: Outcomes of clinical simulation for novice nursing students: Communication, confidence, clinical judgment. Nursing education perspectives 2009, 30(2):79-82.

9. Brooks KL, Shepherd JM: The relationship between clinical decision-making skills in nursing and general critical thinking abilities of senior nursing students in four types of nursing programs. Journal of Nursing Education 1990, 29(9):391-399. 
10. Bowles K: The relationship of critical-thinking skills and the clinical-judgment skills of baccalaureate nursing students. Journal of Nursing Education 2000, 39(8):373-376.

11. Martin C: The theory of critical thinking of nursing. Nursing education perspectives 2002, 23(5):243247.

12. Ludin SM: Does good critical thinking equal effective decision-making among critical care nurses? A cross-sectional survey. Intensive \& critical care nursing 2018, 44:1-10.

13. Lee DS, Abdullah KL, Subramanian P, Bachmann RT, Ong SL: An Integrated Review of the Correlation between Critical Thinking Ability and Clinical Decision-Making in Nursing. Journal of Clinical Nursing 2017, 26(23-24):4065-4079.

14. Chang MJ, Chang YJ, Kuo SH, Yang YH, Chou FH: Relationships between critical thinking ability and nursing competence in clinical nurses. J Clin Nurs 2011, 20(21-22):3224-3232.

15. Chabeli M: Facilitating critical thinking within the nursing process framework: A literature review. Health SA Gesondheid 2007, 12(4):69-89.

16. Bittencourt GKGD, Crossetti MdGO: Critical thinking skills in the nursing diagnosis process. Revista da Escola de Enfermagem da USP 2013, 47(2):341-347.

17. Huckabay LM: Clinical reasoned judgment and the nursing process. Nursing Forum 2009, 44(2):7278.

18. Lunney M: Use of critical thinking in the diagnostic process. International journal of nursing terminologies and classifications 2010, 21(2):82-88.

19. Profetto-McGrath J, Hesketh KL, Lang S, Estabrooks CA: A study of critical thinking and research utilization among nurses. Western Journal of Nursing Research 2003, 25(3):322-337.

20. Zuriguel-Pérez E, Falcó-Pegueroles A, Roldán-Merino J, Agustino-Rodriguez S, Gómez-Martín MdC, Lluch-Canut MT: Development and Psychometric Properties of the Nursing Critical Thinking in Clinical Practice Questionnaire. Worldviews on Evidence-Based Nursing 2017, 14(4):257-264.

21. Facione P, Facione N: The California Critical Thinking Dispositions Inventory (CCTDI); and CCTDI Test Manual, Millbrae, CA: California Academic Pres. In.; 1992.

22. Facione N, Facione PA, Winterhalter K: The health sciences reasoning test: test manual. In.: CA: California Academic Press LLC., San Jose; 2010.

23. Watson G: Watson-Glaser critical thinking appraisal: Psychological Corporation San Antonio, TX; 1980.

24. Carter AG, Creedy DK, Sidebotham M: Evaluation of tools used to measure critical thinking development in nursing and midwifery undergraduate students: a systematic review. Nurse Educ Today 2015, 35(7):864-874.

25. Sousa VD, Rojjanasrirat W: Translation, adaptation and validation of instruments or scales for use in cross-cultural health care research: a clear and user-friendly guideline. Journal of evaluation in clinical practice $2011,17(2): 268-274$.

26. Lynn MR: Determination and quantification of content validity. Nursing research 1986:382-386. 
27. Polit DF, Beck CT, Owen SV: Is the CVI an acceptable indicator of content validity? Appraisal and recommendations. Research in nursing \& health 2007, 30(4):459-467.

28. Hu Lt, Bentler PM: Cutoff criteria for fit indexes in covariance structure analysis: Conventional criteria versus new alternatives. Structural equation modeling: a multidisciplinary journal 1999, 6(1):1-55.

29. Schreiber JB, Nora A, Stage FK, Barlow EA, King J: Reporting structural equation modeling and confirmatory factor analysis results: A review. The Journal of educational research 2006, 99(6):323338.

30. Terwee CB, Bot SD, de Boer MR, van der Windt DA, Knol DL, Dekker J, Bouter LM, de Vet HC: Quality criteria were proposed for measurement properties of health status questionnaires. Journal of clinical epidemiology 2007, 60(1):34-42.

31. Gorsuch RL: Factor Analysis (2nd ed.): Hillsdale: Lawrence Erlbaum Associates.; 1983.

32. Helsinki Declaration: Ethical principels for medical research involving human subject. 2013.

33. Waltz CF, Strickland OL, Lenz ER: Measurement in nursing and health research: Springer publishing company; 2017.

34. Zuriguel Pérez E: Evaluación del pensamiento crítico en enfermería: construcción de un cuestionario basado en el modelo circular de Alfaro-LeFevre. Tesis Doctoral, Universidad de Barcelona (Evaluation of Critical Thinking in Nursing: A Construction based on Circular Alfaro-LeFevre Model Questionnaire). http://www.tdx.cat/ handle/10803/394049. Accessed 1 May 2017.; 2016.

\section{Figures}




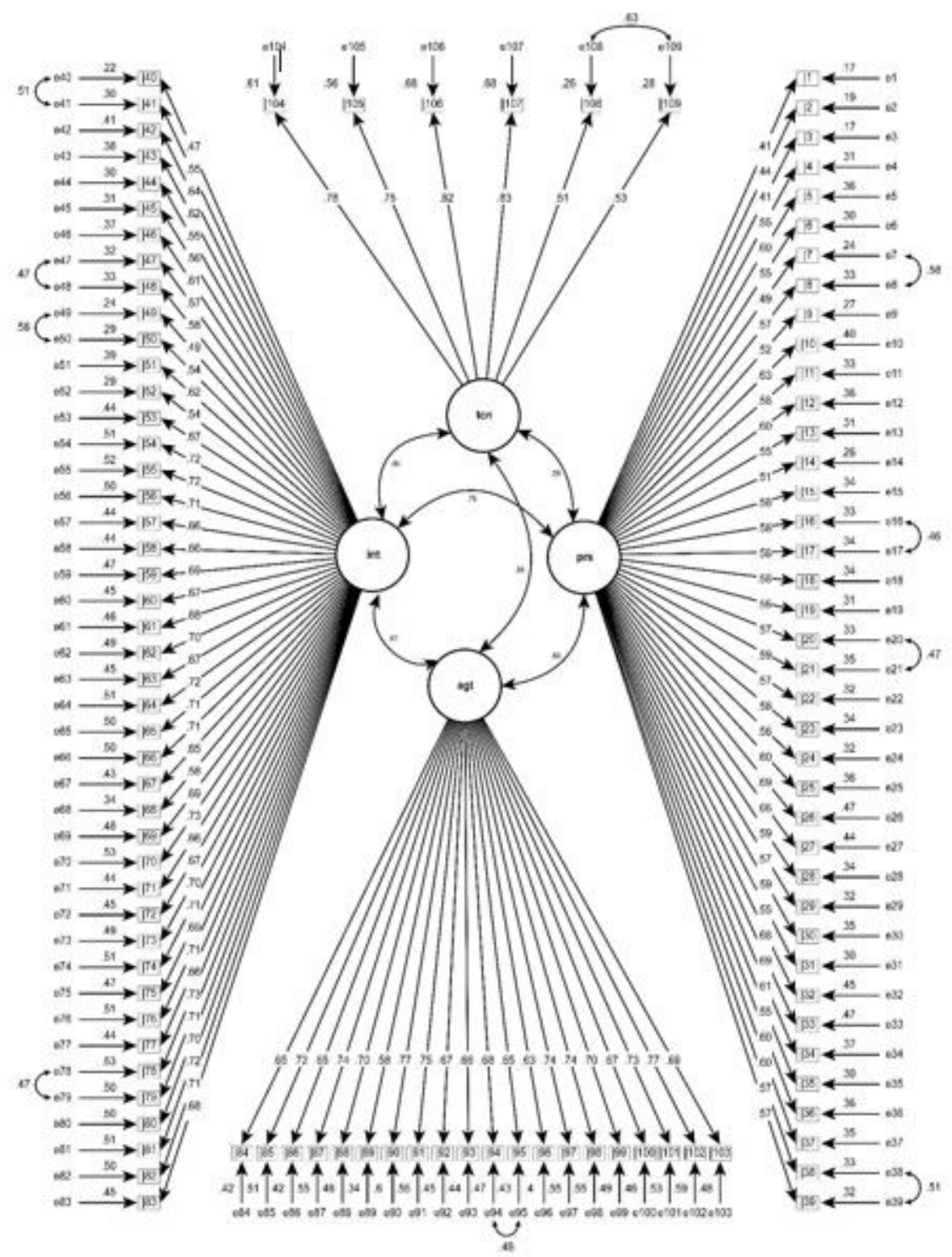

\section{Figure 1}

Confirmatory Factor Analysis Model for the V-N-CT-4 Practice Note: I: item; e: error of unobserved variables; prs: Personal dimension; int: Intellectual and cognitive dimension; atg: Interpersonal and selfmanagement dimension; tcn: Technical dimension. 